\title{
Prenatal diagnosis: whose right?
}

\author{
David Heyd The Hebrew University of ferusalem
}

\begin{abstract}
The question who is the subject of the right to prenatal diagnosis may be answered in four ways: the parents, the child, society, or no one. This article investigates the philosophical issues involved in each of these answers, which touch upon the conditions of personal identity, the principle of privacy, the scope of social responsibility, and the debate about impersonalism in ethics.
\end{abstract}

\section{Prenatal diagnosis: parental v paternal perspectives}

Philosophers are often invited to contribute their analytical skills to the public discussion of normative dilemmas in medical practice. Their input typically consists of the application of general abstract principles to concrete cases, that is, the examination of new practical problems in the light of well-established theoretical concepts and principles. Thus, we apply the principles of autonomy or non-maleficence, professional responsibility or social utility, to problematic cases in ever-changing medical practice. However, the encounter of philosophy with medical ethics does not always have this uni-directional nature. Some of the most pressing issues that arise in modern medicine do not merely call for philosophical illumination but equally challenge conventional philosophical wisdom. Thus, the traditional concept of death is exposed to philosophical re-consideration by the medical definition of brain-death; pregnancy in a surrogate woman questions our firm concept of motherhood, as cloning will probably question our deepest convictions about parenthood in general; modern, long-term medical experimentation introduces a new philosophical dimension regarding the use of present people for the benefit of future generations. But the deepest challenge to philosophical theory comes from the new technologies in human reproduction and genetic intervention. These involve radical changes in the theory of value, in the criteria of personal identity, and indeed in the

\section{Key words}

Prenatal diagnosis; rights. delineation of the scope of moral principles $\mathrm{Nin}_{\mathrm{n}}$ general.

Prenatal diagnosis is an issue in which medifgal concern and philosophical deliberation can entieh each other in a bi-directional relation. The questions it raises relate not only to the application of the rights of fetuses, the duties of parents and doctofs, and the interests of society, but no less to the vêry applicability of these concepts. Medical practitioners would usually direct their interest to the former, and philosophers to the latter; but the distinctignofis somewhat artificial, particularly in the conte $\mathrm{t}^{\circ}$. interdisciplinary exchange. The focus of this artis 1 is the concept of right, which is the key moral concepsin modern liberal discourse and the basis for assesss. the ethical validity of medical practice. Howeveroin the context of the creation of human beings, whic/ is the background to the exercise of prenatal diagno $\vec{s}$, the application of the concept of right will be shown to encounter conceptual and moral obstacles.

By sheer linguistic coincidence the terms 'prenatal', 'parental', and 'paternal' are formed in the English language by different combinations. the same letters. This happenstance may be usefufin distinguishing between two basic ethical perspectiyès on the question of prenatal diagnosis. The parenal point of view takes the parents as either the subjects of the right or the guardians of the child who is the subject of the right. The paternal, or rateger paternalistic, approach regards the issue of prenatal diagnosis as a matter of value which should be decided independently of the rights of the parents and children, that is to say, by appealing to an imporsonal point of view. On the basis of this distinction the following discussion is divided into four sections, each constituting an answer to the question: 'WhEis the subject of the right to prenatal diagnosis?':

1. The parents

2. The child

3. Society

4. No one

This taxonomy is of normative importance in forming practical guidelines for the procedure of 
prenatal diagnosis. However, it is no less significant in highlighting the abstract philosophical problems of applying the language of rights to the issue at hand. The first three options assume the existence of a 'subject' to which rights can be ascribed; but of these only the first two are individual subjects; and of these two only the first is an actual, existing moral person. Thus, only the first option accords with the standard criteria for ascribing rights. The second raises the issue of the moral status of potential or possible human beings. The third raises the question of the status of collective entities. And the fourth casts doubt regarding the relevance of the notion of rights to the whole issue.

\section{The standard model: parental rights}

Living individual human beings are considered the standard carriers of rights. In the liberal tradition the rights of individuals have become one of the most powerful of moral arguments and their respect a basic moral and political imperative. In the sphere of medical therapy the traditional paternalistic approach has given way to the principle of autonomy or the right of the individual patient freely to choose the nature and scope of treatment. In many respects this model of relationship is of a 'consumerist' character: the patient is buying a service from the medical practitioner, and consequently has - within certain limits and constraints - the right to decide the kind of treatment. Prenatal diagnosis can thus be viewed as a kind of quality control in the process of production.

Now, beyond the well-known weaknesses of this consumerist model in the context of doctor-patient relationships, the problem is that unlike most other cases in medical practice, in prenatal diagnosis the buyers of the service are not the patients themselves. That is to say, though the parents are the natural candidates for the ascription of rights, they are not the direct objects of the medical procedure, namely the diagnosis. One immediate retort would be that though the parents of a fetus suspected of being affected with Down's syndrome are not the 'patient', they can be naturally viewed as the patient's guardians. And indeed they are often so regarded by both the law and the medical practitioner. But the logical basis of such a relationship of custody presupposes that the fetus whose rights are 'guarded' can in principle be the subject of such rights, and as we shall see in the next section, this is a highly contested assumption.

So let us reflect on the proposition that the parents are the direct claimants of the right to have their fetus/child diagnosed. The obvious, though by no means trivial, justification for ascribing this right to the parents is that they are the creators of the child. It is their business in the deep sense to control not only the conception, gestation and birth of the child, but to guarantee that they 'get' a healthy child.
Most people recognize the wish to produce a healthy child as a legitimate concern of the parents, who are not only the chief beneficiaries of the act of procreation but also the responsible parties for the outcome. The persons who are going to carry the burden of raising a handicapped child have the right either to prevent the birth of the child or at least prepare themselves for the difficulties involved. Once parenthood is regarded as an autonomous decision of responsible couples (rather than a religious duty or a natural force majeure), the right of parents to prenatal diagnosis cannot be treated as a manifestation of crude consumerism.

Furthermore, the parents are not merely the closest party to the subject of the medical intervention: they are in an important sense its subject. Prenatal diagnosis is applied to a zygote, or to a preembryo, which consists of genetic material from both parents, material which strictly speaking 'belongs' to them. Moreover, the emerging embryo is at least initially part of the body of the mother carrying it, a tissue in her body. So there is a medical and even a metaphysical sense in which it is the parents, no less than the embryo, who are the subject of the diagnosis, and consequently the subject of the right to have or to refuse to have it. The clearest cases illustrating this point of view are genetic counselling and examinations performed before conception, but early detection of possible diseases by means of chromosomal analysis and genetic probes should be equally treated as applied (also) to the parents.

It is, therefore, almost universally agreed that prenatal diagnosis and the treatment following it cannot be exercised against the will of the parents. But, as we shall see, there may be competing rights and interests of other parties - mainly the future child and society - which could come into conflict with the parents' wishes. Our liberal ethos typically gives priority to the parents' rights, since they are actual rather than potential beings, since they are identifiable individuals rather than vaguely defined collective entities, and since their choice as actual individuals is protected by the principle of privacy which gives priority to individual will over competing social or abstract values. However, the interests of the future child (which will be discussed in the next section) and those of society (which will be discussed in the sequel) challenge this priority, in the name of the individual (liberal) rights of the fetus and in the name of allegedly weightier social interests.

\section{The contested view: fetal rights?}

Can a child sue its parents or its doctor for having failed to diagnose a disease which makes its life miserable? This is the subject of the well-known 'wrongful life' cases, which have plagued the legal systems of many western countries in the past thirty 
years. The most difficult cases concern 'pre-conception' diagnosis, namely negligent genetic screening or counselling which leads to the conception and birth of a handicapped child which otherwise would not have been conceived at all (1). But here we are concerned with prenatal diagnosis, that is, the alleged right of the child already conceived to be screened and tested for diseases such as Tay-Sachs, which would make its life not worth living. In this view, early detection of serious diseases is treated as something which is owed to the child. The assumption in all these cases is that positive results of the relevant medical or genetic test would lead to abortion, ie to the non-existence of the subject of the right. But this claim is based on the striking argument that people have among their rights also the right not to come into existence, not, in certain circumstances, to be born.

Unlike the right of parents to have their child aborted, which is conceptually coherent though morally controversial, the right of a fetus not to evolve into a full human being is logically disputable. For, if the fetus is a person having moral standing, then it is not clear what could be meant by the right not to be born, not to come into existence (2). And if it is not a person, how can it have any rights? The remaining alternative is to view the fetus's right as a right to early euthanasia. However, this suggestion is highly artificial, since euthanasia is usually recognized as the right of people expressing an explicit wish to die, and the rare cases in which euthanasia is applied to unconscious patients in a vegetative state are not justified in terms of 'rights'.

To highlight the absurdity of prenatal diagnosis as a fetal right, take the standard in vitro fertilization (IVF) practice in which seven ova are fertilized. A few days later they are all carefully examined and only three healthy-looking ones are selected for implantation in the mother's uterus. Can we seriously say that by diagnosing the defective embryos we respect their right not to exist, to be discarded? Or, alternatively, do all the seven have the right to be 'diagnosed' so as to avoid later wrongful life claims? A child cannot complain of having been born deaf to a mother who was suffering from German measles, since had the mother waited and conceived only after recuperating from her disease, it would have been another child which would have been created (3).

But of course there are cases of prenatal diagnosis in which the aim is not the abortion of the positively diagnosed fetus but certain curative or corrective measures which could lead to the better health of the future child. Can the fetus in those cases be said to hold a right to the relevant test or genetic probe? Even these cases are not as clear as they might look at first sight. Indeed, if by chromosomal analysis the defective gene responsible for a syndrome such as spina bifida can be identified and removed without leading to the death of the embryo, it seems that not only is it the duty of the doctor to do this, but it may be viewed as the right of the developing child (4). N doubt it would make sense to allow legal standing the child who would sue the doctor for neglecting apply such a procedure once the child was born win this serious handicap. The reasoning would be that the child could have been better off had the defectie gene been removed.

But what about deeper genetic interventions which would mean a complete change in the subject's identity? Sex selection or the genefic control of sexual orientation, which may be called 'identity-fixing properties' of the fetus, may serve us in our so far fictitious thought-experime $\overrightarrow{a b}$. Assuming that in a particular patriarchal socies males are better off than females in their life prospects and that the sex of a child can not only be diagnosed but also decided early in pregnancy, 厉 children have the right to be born male? The air iof paradox characterizing this possibility is connected with the metaphysical fact that gender is constit tive of identity and hence cannot be ascribed to an identifiable subject as a right (5).

\section{The Platonic view: the paternalistic rights of society}

In his Republic Plato outlines in detail the metho्ष procreation for the 'guardians' as fully subordint to social interests. Thus, the state is responsible only for the education of children, but also for the process leading to their creation. By selectione marriages the genetic health of the offspring as guaranteed, and the procreation of defective childrgn is considered a violation against society (6). Although Plato's political utopia is one of the most extreme formulations of the idea that society has sovereignty over human reproduction, there have been many ideologies, not necessarily totalitarian, which hape granted the state a say in reproductive choices. $N_{y}$ suggestion is that even from a liberal point of vien society has a standing regarding the practice \&f prenatal diagnosis and the treatment following it.

First, it is a fundamental tenet in most systems of criminal law that society has 'an interest' in the prestection of the life of its citizens, that is, a paternaliste right to defend and enhance life independently of the interests and wishes of individuals. The restriction of abortion (and of course of suicide), the regulation of euthanasia (even the 'voluntary' kind), are examples of the exercise of this state authority. Secondly, even in a typically liberal society the state may interfere with the actions of individuals if they have comsequences which might be significantly costly to society. The birth of a child with Down's syndrome or spina bifida puts a heavy burden on pubsc resources in any welfare state and hence provides the state with grounds for regulating by direct a ad indirect means the medical practices which might reduce these costs. On this basis the state may be justified in financing amniocentesis and genetic 
screening, and in principle in punishing or suing for damages in the case of negligence leading to the birth of defective children. The balance between the interests of society and the principle of individual privacy is shaky and contested (7), but it is hard to deny any right to society once the individual is granted certain rights to be assisted by social resources.

Furthermore, only within the political framework can the issues of demography, eugenics, or the proportion of men and women in the population be resolved (8). These are all problems which can be tackled collectively, that is by means of a social contract or the democratic process. The dangers of unco-ordinated individual choices on matters which decide the quality of life of future generations can only be checked by centrally regulated government action. In that respect, prenatal diagnosis and treatment will in the future become similar to immunization policies which are enforced by law in order to protect public interests. In another respect, economic constraints on the universal accessibility to prenatal diagnosis make it necessary for society to determine priorities (based on costs, on the severity of the disease, on the degree of risk to which the fetus and mother are exposed, the chances of therapy, etc) (9). Thus, the parental rights of individuals are inevitably constrained by the paternal rights of society (10).

\section{The impersonal perspective: the irrelevance of rights}

The last of the four options for dealing with the ethics of prenatal diagnosis completely denies the relevance of the discourse of rights. Essentially, the thesis is that the language of rights is inappropriate for dealing with the complex of issues regarding the morality of procreation, since rights can be ascribed only to actual individuals. As we have shown, the fetus is only a potential (rather than actual) individual human being, and society, though 'actual' is a collective entity rather than an individual. This leaves us with the parents, who indeed are actual individuals, but are only indirect beneficiaries of prenatal diagnosis. What is consequently called for is a radical conceptual shift, substituting the language of value for the language of rights.

This shift involves a deep philosophical issue relating to the nature of value: is 'good' necessarily related to human beings and the way their interests, rights, wishes and ideals are served; or is 'good' the property of the world, that is, independent of the will of actual human beings? The first view, which has been called 'person-affecting', holds that 'good' is always 'good for', whereas the second, impersonal view, holds that states of affairs can be said to be good tout court, as such. I cannot elaborate here on this abstract theoretical distinction, but will only add that the morality of procreation is exactly one of the decisive test-cases for the two theories of value. Both have their own attractions as well as their difficulties, arising out of the counter-intuitive implications of their consistent application (11).

The impersonal approach to prenatal diagnosis and treatment analyses the potential benefits versus the risks, both to the individual growing human being and to its parents and society, balancing them in an overall calculus attempt to reach a normative solution. Classical utilitarianism is the best-known moral theory based on this impersonal approach. But impersonal values can equally be of a nonutilitarian nature, for example, religious or aesthetic. The sum total of good in the world (whatever its nature) is the only guiding principle, and should override considerations of individual rights. Thus, particular choices regarding genetic screening, the selection of embryos for implantation, and abortion, as well as general policies regarding these issues should be governed by impersonal values. The wrongness of negligent prenatal diagnosis is, accordingly, not derived from the violation of the rights of any party, but from the intrinsic badness of the state of affairs created by it (12). Thus, the fact that the severely handicapped child does not as a matter of fact regret having been born does not mean that the medical negligence which led to the child's birth is not blameworthy or even punishable.

\section{Conclusion: whose right? who is right?}

The use of modern techniques for diagnosing homosexual tendencies in the fetus is a good example of the ethical dilemmas of prenatal diagnosis and the theoretical problems in their resolution. All the four options which have been sketched here play a role in the debate, which, though of only theoretical interest at this stage, may soon become practically relevant. Let us assume that sexual orientation can be diagnosed by amniocentesis early in gestation and changed by means of a single androgen injection administered during the critical stage of brain development. Should this be done at all? Should the diagnosis be made if it is known that the parents would abort the fetus in the case of a positive result (13)? And whose right is it? If homosexuality is a property which constitutes one's identity, it is doubtful that any homosexual can seriously want to have been born heterosexual, for this would mean that he or she would have been a different person. And if it is not an identity-fixing property, then one could say that one would have been better off with another sexual preference. But does this mean that people have a right to have their genetic make-up changed accordingly? First, it is not clear that we have a basis for claiming that homosexuality is a tendency which is objectively inferior to heterosexuality; and secondly, even if it were so, it is not clear that people have a sweeping right to any property which would make them better off. 
Parents, of course, may want to decide the sexual orientation of their offspring (14). Do they have the right to do so? On the one hand, having control of the very conception of the child and over much of its identity, there seems to be no reason that sexual tendency should not be included in the scope of parental power. But some people feel that even if fetuses' rights cannot constrain parental rights, there are other grounds for the prohibition on parents' intervention in the natural process of human reproduction. This is the famous argument against 'playing God'. It appeals to the impersonal value of leaving natural processes either completely beyond human interference or at least beyond medical intervention in cases which are not clearly 'pathological'. Most medical practitioners and geneticists seem to hold some version of the latter option, though formulating the criteria for pathology is notoriously difficult.

From society's point of view the prevention of homosexuality may be considered in either positive or negative terms. On the one hand, homosexuality could reduce fertility in a society which is badly in need of population growth. On the other hand, active steps to reduce the number of homosexuals may be seen as a threat to the status and prospects of the existing homosexual community, which deserves respect from society (15). Finally, from an impersonal perspective, homosexuality may be treated either as a sin against God, a deviation, a pathology, whose eradication must be welcome, or alternatively as an intrinsically worthy way of life, enriching cultural and social forms, and hence its elimination as a loss 'to the world'.

Who is right? My own view, which I have tried to defend in detail elsewhere (1), is that the personaffecting theory of value is superior to its impersonal rival, and hence that the fourth option should be ignored. Within the three remaining alternatives, the rights of the fetus seem to be the most problematic, logically speaking, since it is merely a potential being or at most an emerging person. We should, therefore, negotiate carefully between the rights of the parents and those of society. The closer we are to a liberal conception, the wider will be the freedom of the parents in exercising their rights to decide the nature of their child, even against conflicting social interests. The more we approach a monolithic view of what is good for people, the wider the sphere of the right of society to impose that view on individual members. This balancing of individual preferences and social goals is a never-ending enterprise, in which both scientific and normative considerations lead to ever-changing solutions.

David Heyd, DPhil (Oxon), is Professor of Philosophy at the Hebrew University, ferusalem, Israel.

\section{References and notes}

(1) These 'pure' cases are discussed in my Genethics: moral issues in the creation of people. Berkeley: University of California Press, 1992: ch 1.

(2) And consider the question: against whom is the right maintained? Is it only the doctor or also the mother? Can a child sue its own mother for not having abor it 'in time'? For the moral dangers involved in the extension of wrongful-life claims from doctors go parents (particularly for the parent-children relationship), see Elias J, Annas G. Reproductive genetics add the law. Chicago: Year Book Medical Publishefs, 1987: 119-120. There have already been casesoin which children tried to sue their mothers for having caused them harm by smoking or using drugs duripg pregnancy.

(3) Parfit D. Reasons and persons. Oxford: Clarendon Preges, 1984: ch 16. Parfit was the pioneer in the discussion of the ethical implications of cases in which an action only affects a person but modifies his or her identity.

(4) Kahn J P believes that even when we cannot speakof 'harming conditions' (when there is no identifiakle subject to whom the harm is done), we may speaksf 'harmful conditions', namely conditions the creation of which would put the child, after birth, into an inferior position in its life. See his Genetic harm: bitten by the body that keeps you? Bioethics $1991 ;$; 289-308. I am not sure, however, that this distinctin can solve the paradox of wrongful life claims.

(5) For a convincing presentation of this thesis, see Zohar N. Prospects for 'genetic therapy' - can a persen benefit from being altered?; Bioethics 1991; 5:Q288. Zohar argues that when genetic intervention lead toa change in identity, it cannot be called 'therapyô. the biological subject cannot be regarded as a 'parient'.

(6) Plato. Republic, St. 461 a-c. In: Hamilton E, Cairns \$II, eds. The collected dialogues of Plato. Princetक्षि: Princeton University Press, 1963. 'Then, if anyohe older or younger than the prescribed age meddles wh procreation for the state, we shall say that his erroßis an impiety and an injustice, since he is begetting the city a child whose birth, if it escapes discovery, wall not be attended by the sacrifices and the prayers which the priests and priestesses and the entire city preferthe ceremonial marriages' [my emphasis].

(7) There is a difference between state-controlled euge programmes and individual effort to secure the birth of a child with certain properties, by the parents. Repugnance towards the former is associated with the suspicion in which we hold any totalitarian attempto create human beings of the same kind, or of the kinteds which are beneficial 'to society'. The legitimacy of 트e latter is connected to the liberal freedom of the individual to plan his or her own life. See, for instance, Harris J. The value of life. London: Routledge, 19s: 150.

(8) Thus, for instance, a Norwegian committee recoefmends that 'sex determination tests will be allowed only in serious sex-related diseases'. Report no 25 ţo the Storting. Biotechnology related to human beings. O\&O Ministry of Health and Social Affairs, 1992-1993: 48.

(9) The Norwegian committee mentioned above flatly rejected the "trend in prenatal diagnosis whose objecktive would be systematically to avoid the birth of individuals with genetic diseases or developmengal anomalies purely for cost-benefit or other socijoeconomic reasons'. See reference (8): 46.

(10) Mathieu D. Preventing prenatal harm. Dordrecht: Kluwer, 1991. This is a book devoted to the question 
of state intervention in prenatal treatment. Should mothers be forced by the state to behave in ways which would secure the child's future health? Mathieu's conclusion is that the language of rights is insufficient to account for the complexity of the problem, and that there is an intricate balance between fetal and parental claims and interests as well as between individual freedom and state-enforced social values.

(11) Most of my book Genethics [see reference (1)] is devoted to the systematic examination of the implications of person-affecting versus impersonal theories of value in the sphere of procreation. See particularly pages $80-90$.

(12) A typical impersonal value in our context is the quality of the gene pool over which we are exercising growing control. On the one hand, we feel that medicine should be responsible for preventing the spread of genetic malformations in future society. On the other hand, we equally shudder at radical eugenic ideas. However, some scientists treat the latter apprehension as a popular reaction to scaremongering, since only if most people reproduce by artificial (IVF) methods is there any danger that the gene pool will be significantly affected. See also Ferguson $\mathbf{M}$. Contemporary and future possibilities for human embryonic manipulation. In: Dyson A, Harris J, eds. Experiments on embryos. London: Routledge, 1990: 6-16.
(13) This intriguing example is drawn from Murphy T F. Reproductive controls and sexual destiny. Bioethics 1990; 4: 121-142. Murphy's thesis is that this practice should be considered 'heterosexist' and consequently resisted morally, though not criminalized, see page 122 .

(14) Murphy refers to empirical studies which showed that most homosexual subjects did not regret having their particular sexual orientation, though many parents for various reasons - preferred their prospective children to be born heterosexual. See reference (13): 123-124. This confirms the asymmetry for which I am arguing between the point of view of the parents and that of the subject/child.

(15) The argument from discrimination has often been raised by groups of handicapped people who feel that the active prenatal attempt to prevent the birth of handicapped people indicates an intolerant attitude on the part of society towards members of this group. Unlike Murphy I strongly object to this argument, which seems to rest on a fallacy: the fact that I want a son does not indicate male chauvinism; my preference for an intelligent girl does not imply intolerance of silly women; a parental concern for the health of a future offspring does not equally mean a discriminatory view of handicapped people.

\section{News and notes}

\section{Hippocrates and modern medicine}

The Francis Clark Wood Institute for the History of Medicine of the College of Physicians of Philadelphia will hold a conference on the theme of Hippocrates and Modern Medicine, on 4-5 May 1996. Pre-circulated papers will explore the multiple meanings, constructions, and uses of Hippocrates and Hippocratic medicine since the seventeenth century in a variety of national contexts.
Registration is limited. For further information contact Monique Bourque, Ph D, Assistant Director for Programs, Wood Institute, College of Physicians of Philadelphia, Philadelphia, PA 19103, (215) 563-3737 (phone); (215) 561-6477 (fax); or bourque@hslc.org (email). 